\title{
Hidden library: visualizing fragments of medieval manuscripts in early-modern bookbindings with mobile macro-XRF scanner
}

\author{
Jorien R. Duivenvoorden ${ }^{1 *}$, Anna Käyhkö ${ }^{2}$, Erik Kwakkel ${ }^{2}$ and Joris Dik ${ }^{1}$
}

\begin{abstract}
This experiment demonstrates the large potential of macro-XRF imaging for the visualization of fragments of medieval manuscripts hidden in early-modern bookbindings. The invention of the printing press in the fifteenth century made manuscripts obsolete and bookbinders started recycling their strong parchment leaves to reinforce bindings of printed books. One in roughly every five early-modern books contains a fragment of a medieval manuscript hidden underneath the bookbinding. Systematically investigating these fragments will provide scholars with valuable information about transmission and variant readings of medieval texts. Four case studies were scanned with a Bruker M6 Jetstream mobile XRF scanner. We were able to visualize hidden texts underneath black paint, paper and parchment at such a high resolution that they could be read and dated. One of the findings was an early twelfth-century excerpt of a text by the Venerable Bede in a sixteenth-century bookbinding. In addition, we were able to separately visualize the lower and upper text of a famous palimpsest. The main limitation of the current set-up is the scanning time, which took anywhere between 6 and $66 \mathrm{~h}$. In order to systematically employ macro-XRF for researching medieval fragments, the scanning time needs to be decreased. Nonetheless, this experiment shows that the macro-XRF technique is extremely suitable for visualizing fragments of medieval manuscripts in a non-destructive way in order to read, date and localize them.
\end{abstract}

Keywords: Medieval manuscripts, Macro X-ray fluorescence scanning, Fragments

\section{Background}

The invention of the printing press in $c .1450$ made the handwritten medieval book-or "manuscript"-obsolete. As Europe started to read the printed counterparts, handwritten books lost their value and many of them were destroyed. Over the course of the sixteenth and seventeenth century, many thousands were boiled down for the production of glue. Equally many died a different death: their pages were cut out and recycled by bookbinders. These so-called "fragments" were usually cut from parchment books [1]. This material was strong and thus ideal for supporting the bookbinding of printed books. As a result, at present there are thousands of manuscript

\footnotetext{
*Correspondence: jorien.duivenvoorden@gmail.com

1 Department of Materials Science, Delft University of Technology, Mekelweg 2, 2628 CD Delft, The Netherlands

Full list of author information is available at the end of the article
}

pages hidden in post-medieval bookbindings. In this article we present a non-destructive scanning technique to uncover this hidden library.

We estimate that one in every five early-modern books has fragments of medieval manuscripts in its bookbinding. Investigating fragments in a systematic way will allow scholars to explore a new type of research. There are three important reasons why this research matters. First of all, this vast amount of fragments contains valuable information about transmission of medieval texts. The fragment itself may only consist of a few words or lines of text, but it does tell us that this work was known in a certain region at a certain time. Secondly, it will provide scholars with more information about variant readings. Handwritten manuscripts were manually copied and that frequently caused changes in the text, which is why two copies of one text are almost never the same. A fragment could in principle contain a new variant reading, which 
is interesting for researchers of medieval texts, who can divide the readings into families-a field of study that is called stemmatology. Finally, a question that book historians would like to address is which types of manuscripts were cut up and recycled by bookbinders. Was it always the same kind of manuscript or did bookbinders use anything they could get their hands on? A study of fragments in a quantified manner could provide an answer to these kinds of questions.

Macro X-ray fluorescence scanning (MA-XRF) is a frequently employed technique to visualize underlying paintings in painted works of art [2,3]. It is a non-destructive technique that combines elemental analysis with spatial information, resulting in macro-scale elemental distribution maps. Even though MA-XRF has proved to be very valuable for (technical) art historians and art conservators, its possibilities have not been explored yet in the field of book history $[4,5]$. We propose MA-XRF as an excellent technique to investigate hidden fragments in bookbindings, because of the following reasons. First of all, point analysis with micro-XRF has been successfully used for trace analysis in iron gall ink [6]. Iron gall ink is the most commonly used ink in the Middle Ages for the production of manuscripts. It consists mainly of iron and contains traces of elements such as copper, zinc, calcium and manganese [7-9]. Furthermore, the material that covers the fragments is parchment, made from animal skin, or paper, made from dried cellulose pulp. Organic materials such as parchment and paper are not detected by means of XRF. Finally, the spatial information obtained with a scanning technique such as MA-XRF is crucial for the purpose of reading and dating the medieval texts.

To illustrate the potential of MA-XRF for visualizing hidden medieval fragments we present four case studies from the Leiden University Libraries (Fig. 1). These case studies were chosen based on their suitability for scanning and to show the different types of hidden texts. The first case study (cataloged as 635 G 5 in the Leiden University Libraries) is a copy of Marcus Fritsch's Meteororum printed by Johannes Montanus and Ulrich Neuber in the year 1555, the full binding of which is covered with black paint. A closer look reveals parts of script, only visible to a limited extent and not legible. The second case study (603 G 11) is a copy of Catechismus ex decreto concilii tridentini ad parochos by the Council of Trent, printed by Coloniae in the year 1567. Under a paper paste-down, a piece of paper pasted to the inside of the cover, a large fragment is slightly visible under raking light. The third case study (617 F 19) is a copy of Caspar Bartholin's Cum plurimis novis observationibus opinionibus $\&$ controversiarum occurrentium decisionibus adjecto indice capitum \& rerum locupletissimo, printed by Goslar in the year 1632. It contains a fragment under the parchment bookbinding. From the outside the fragment is not exposed, but opening the book reveals the far edge of the fragment. Green and red decorations are still visible. The last case study is the famous "Leiden Palimpsest" (BPG $60 \mathrm{~A}$ ). This is a copy from the second half of the tenth century of all the seven tragedies by Sophocles with lacunes [10]. This palimpsest is the oldest medieval witness of the tragedies of Sophocles and belongs to a traditional branch known only from the twin manuscript now held in Florence, Biblioteca Medicea Laurenziana (Laur. 32, 9). However, the layer of parchment containing the Sophoclean text has been scraped off in order to recycle the leaves. A newer text that contains the works of Anastasios Sinaites, Sophronian patriarch of Jerusalem, and an unpublished treatise On faith by St. Gregory has been written across the traces of the Sophoclean text at the beginning of the 14th century. The Sophoclean text is only vaguely visible in the margins.

\section{Methods}

To collect the data maps, a mobile MA-XRF scanner (Bruker M6 Jetstream) was used. The M6 has a measuring head that moves over the surface in an XY-motorized stage with a minimum step size of $10 \mu \mathrm{m}$ and maximum travel range of $800 \times 600 \mathrm{~mm}(\mathrm{w} \times \mathrm{h})$. Mounted on the measuring head are a Rh-target $\mathrm{X}$-ray tube $(30 \mathrm{~W}$, maximum voltage $50 \mathrm{kV}$, maximum current $0.6 \mathrm{~mA}$ ) and a $30 \mathrm{~mm}^{2}$ XFlash silicon drift detector (energy resolution $<145 \mathrm{eV}$ at $\mathrm{Mn}-\mathrm{K}_{a}$ ) together with two magnifying optical cameras to document the mapped area. The X-ray beam converges in the focal point, at which the minimum beam diameter is $c .40 \mu \mathrm{m}$. The beam diameter can be regulated by adjusting the distance between the X-ray source and the surface [11]. Figure 2 shows a picture of the setup and a schematic representation of the minimum beam diameter that varies with the distance between the X-ray source and the object. To achieve optimally focused scans, the distance between the books and the scanning head was adjusted to minimize the beam diameter (c. 40 $\mu \mathrm{m})$. All case studies were scanned at an X-ray tube voltage of $50 \mathrm{kV}$ and current of $0.6 \mathrm{~mA}$. The scan settings are shown in Table 1.

The data was collected with the Bruker M6 Jetstream software package. Processing of the large XRF data sets was done using datamuncher and PyMca in order to obtain artefact-free elemental distribution maps [12]. In PyMca the statistics-sensitive non-linear iterative peakclipping (SNIP) was chosen as background estimation. The corrected distribution maps were exported to Adobe Photoshop for brightness/contrast manipulation. A few words or lines of the visualized texts were entered in Google Books to identify the text. The scripts were dated by Erik Kwakkel. 

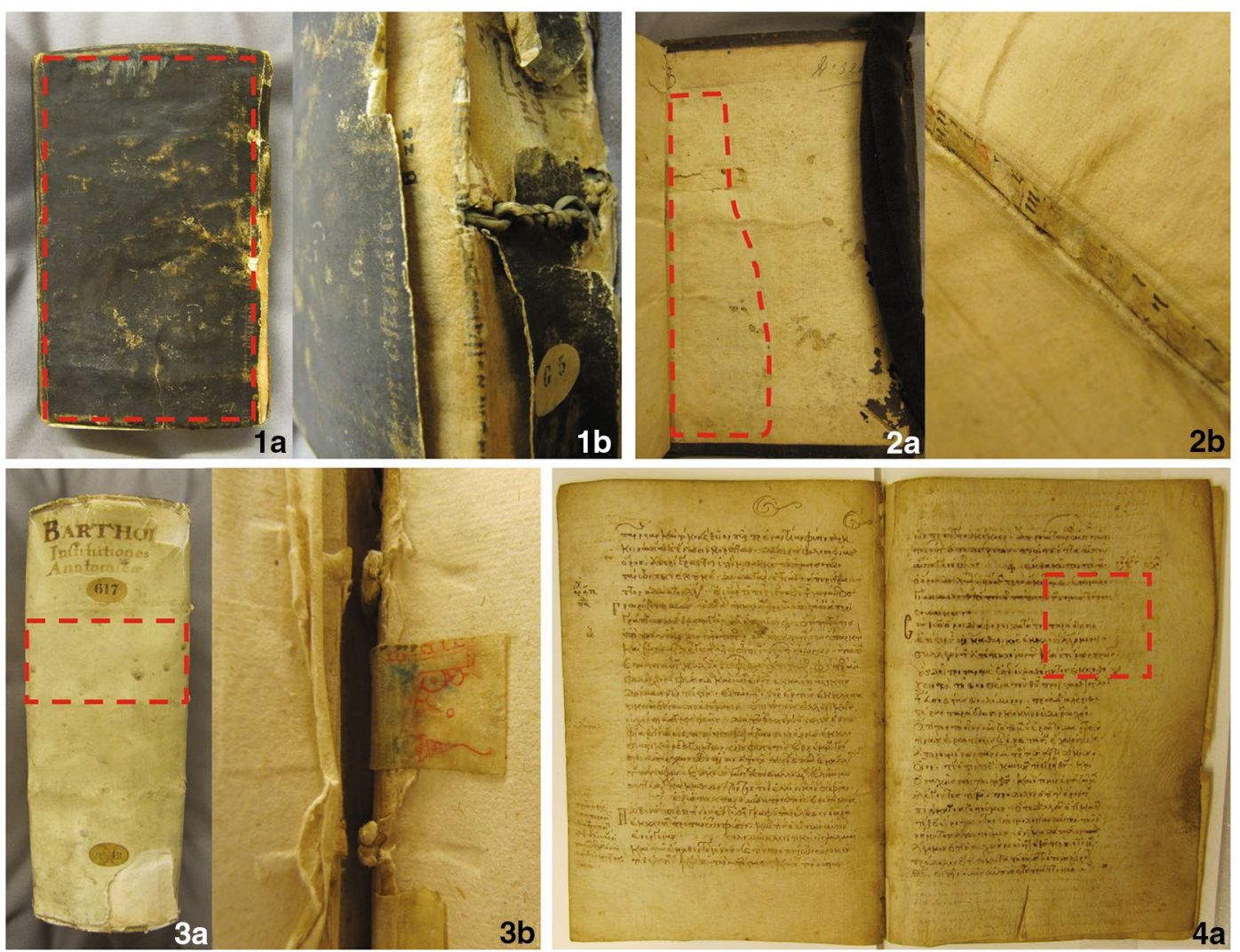

Fig. 1 The four case studies. Scanned areas are indicated with red dashed lines. $635 \mathrm{G} 5$ (1) a) and close-up with script visible (1) b). Scanned area of 603 G 11 under paper (2a) and close-up with script visible (2b). 617 F 19 (3a) with fragment containing red and green ink visible inside the book (3b). Two pages of the BPG 60 A (4a). Courtesy of the Leiden University Libraries

\section{Results}

\section{Case study $1-635$ G 5}

The back cover of this sixteenth-century book is covered by a black paint that obscures most of the underlying script. The MA-XRF distribution maps reveal not only this script, but also other written layers (Fig. 3).

The calcium distribution clearly shows a script divided into two columns. This is a book script from the first half of the twelfth century. A clue to this date is provided by the presentation of letter pair bb ("sabbato" in column 2, line 7), which is still presented separately (Fig. 4a, b). From $c .1150$ this pair would be written as one entity without space, a process called fusion or biting, which is visualized in Fig. 4d [13]. The biting process of the letter pairs bb/pp is illustrated by the two excerpts (Fig. 4c). The letter pair bb occurs less frequently in medieval texts than the letter pair pp, hence Fig. 4c shows the letter pair pp.

The text in the calcium map includes an excerpt of the Homiliae by the Venerable Bede (died in 735), a sermon titled In vigilia paschae. Surprisingly, the ink used in this script contains almost no iron. What the iron distribution does show is a cursive script from the sixteenth century that does not follow the shape of two columns. Furthermore, the mercury distribution map reveals paragraph marks, initials and isolated words from the fourteenth century, most probably written in red ink. The penetrative character of mercury causes these signs to be visible throughout multiple pages of the book. This is the reason why at first sight these characters are randomly distributed (see "Depth" section). Finally, the lead distribution quite clearly shows the lines that were drawn with a pencil lead to indicate the writing lines to guide the handwriting.

\section{Case study 2-603 G 11}

This case study from the sixteenth century contains a rather large fragment under an endpaper that is pasted down to the inside of the cover. The calcium and iron distribution maps show a fifteenth-century page from a calender (Fig. 5). This date is indicated for example by the letters a, $\mathrm{e}$ and $\mathrm{o}$. The mercury distribution map reveals, along with 

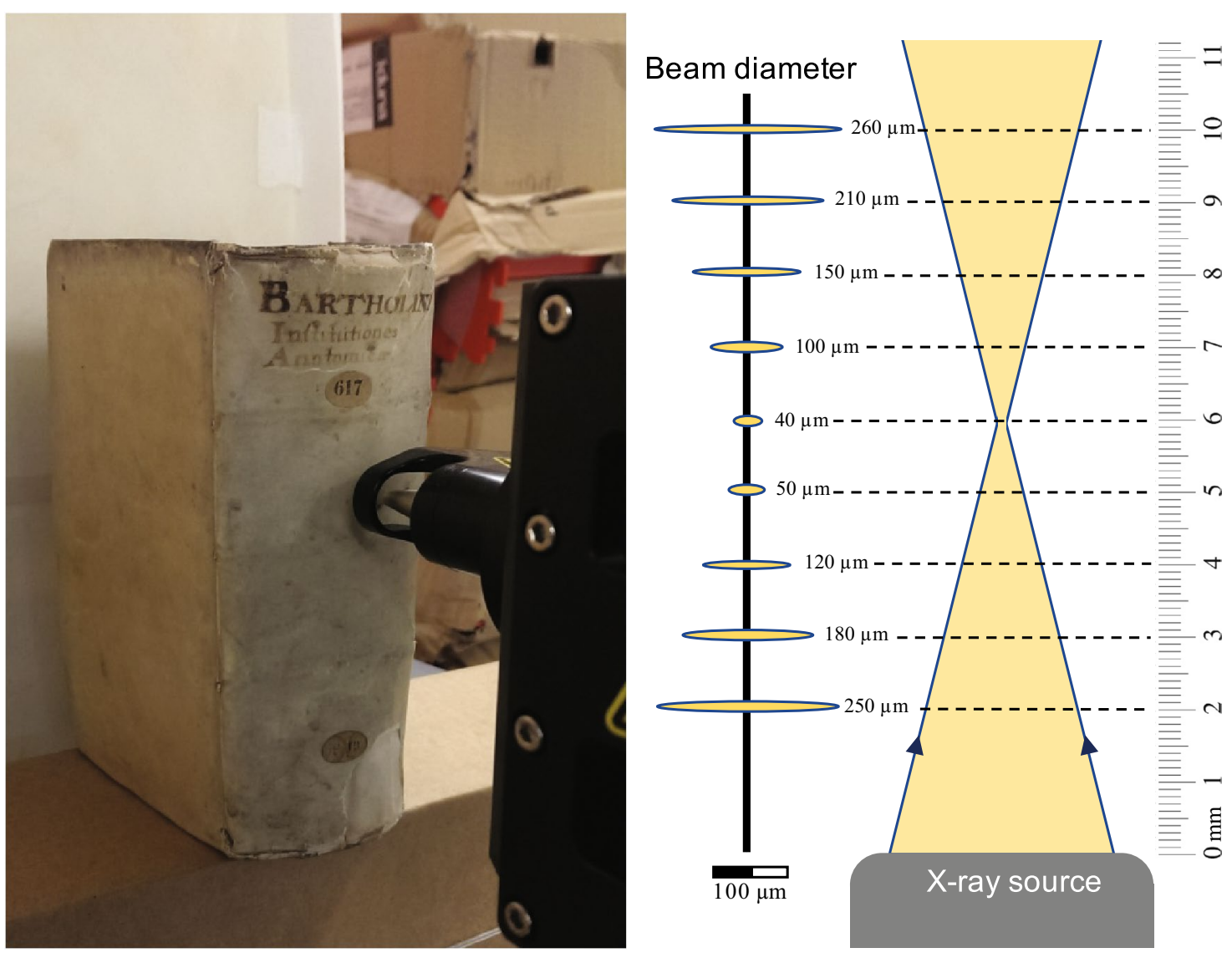

Fig. 2 Representation of scanning set-up. Left picture of the set-up with the scanning head and the object. Right schematic representation of the minimum beam diameter in $\mu \mathrm{m}$ and the distance between the $\mathrm{X}$-ray source and the object in $\mathrm{mm}$. Values are based on measurements by Alfeld et al. [11]

Table 1 Scan settings of the four case studies

\begin{tabular}{lllll}
\hline Case study & Covering material & Step size $(\boldsymbol{\mu m})$ & Dwell time $(\mathbf{m s})$ & Approximate \\
\hline 635 G 5 & Black paint & 200 & 150 & 16 \\
603 G 11 & Paper & 100 & 150 & 21 \\
617 F 19 & Parchment & 150 & 150 & 6 \\
BPG 60 A & No covering material & 80 & 450 & 66 \\
\hline
\end{tabular}

Tube settings were constant ( $0.6 \mathrm{~mA}$ and $50 \mathrm{kV})$

paragraph marks and some isolated words, the word "decollatio", which means beheading, suggesting that the mercury script is a fifteenth-century calender. Calenders were often added to books of hours and other liturgical and devotional texts to help celebrate medieval saints [14]. In this case, "decollatio" most probably refers to the beheading of John the Baptist (celebrated on the 24th of June). This liturgical calender is from the same book as the iron and calcium distribution map, only from a different page. The same hand in the handwriting can be recognized.

\section{Depth}

In the three scans in Fig. 5 a transition from a superficial picture to a more in-depth picture is visible. The calcium map shows only the front side of the fragment, because the fluorescence lines of calcium are relatively weak $\left[3.691 \mathrm{keV}\left(\mathrm{K}_{\alpha 1}\right)\right.$ and $\left.4.012 \mathrm{keV}\left(\mathrm{K}_{\beta 1}\right)\right]$. This means that the fluorescence of calcium in depth is too weak to penetrate the surrounding parchment. Iron fluorescence, however, has higher energy $\left[6.403 \mathrm{keV}\left(\mathrm{K}_{\alpha 1}\right)\right.$ and $\left.7.057 \mathrm{keV}\left(\mathrm{K}_{\beta 1}\right)\right]$ and therefore is able to penetrate more 


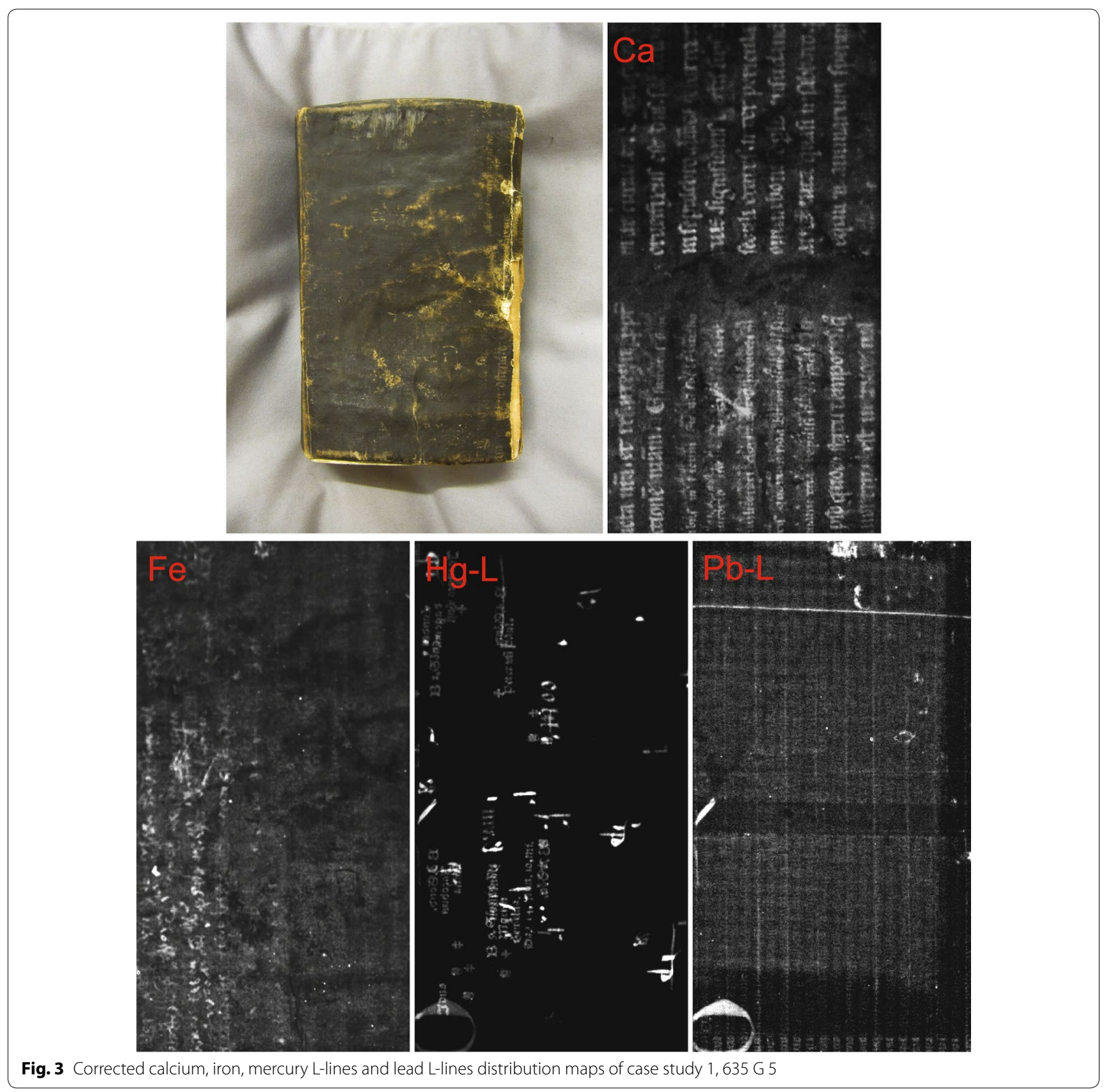

layers of parchment. This results in overlap of text from the front and the backside (recto and verso) of the fragment, which decreases the readability of the text. In theory the backside of the fragment could be retrieved by a series of steps including the creation of a binary mask and subtraction. This problem has been encountered before and image processing techniques such as the pseudo-color technique were employed to enhance readability, but this is outside the scope of this article [15]. Even more penetrating than iron is the much heavier mercury [9.987 $\mathrm{keV}\left(\mathrm{L}_{\alpha 1}\right)$ and $\left.11.823 \mathrm{keV}\left(\mathrm{L}_{\beta 1}\right)\right]$. This is the reason why the mercury distribution map reveals more layers that are hidden inside this book cover. Multiple paragraph marks are visible that seem randomly distributed across the fragment, because they correspond to different layers. We also see some words that are rotated $90^{\circ}$ relative to the word "decollatio". In short, looking at fluorescence lines with increasing energy provides us with an in-depth profile of the fragment. 

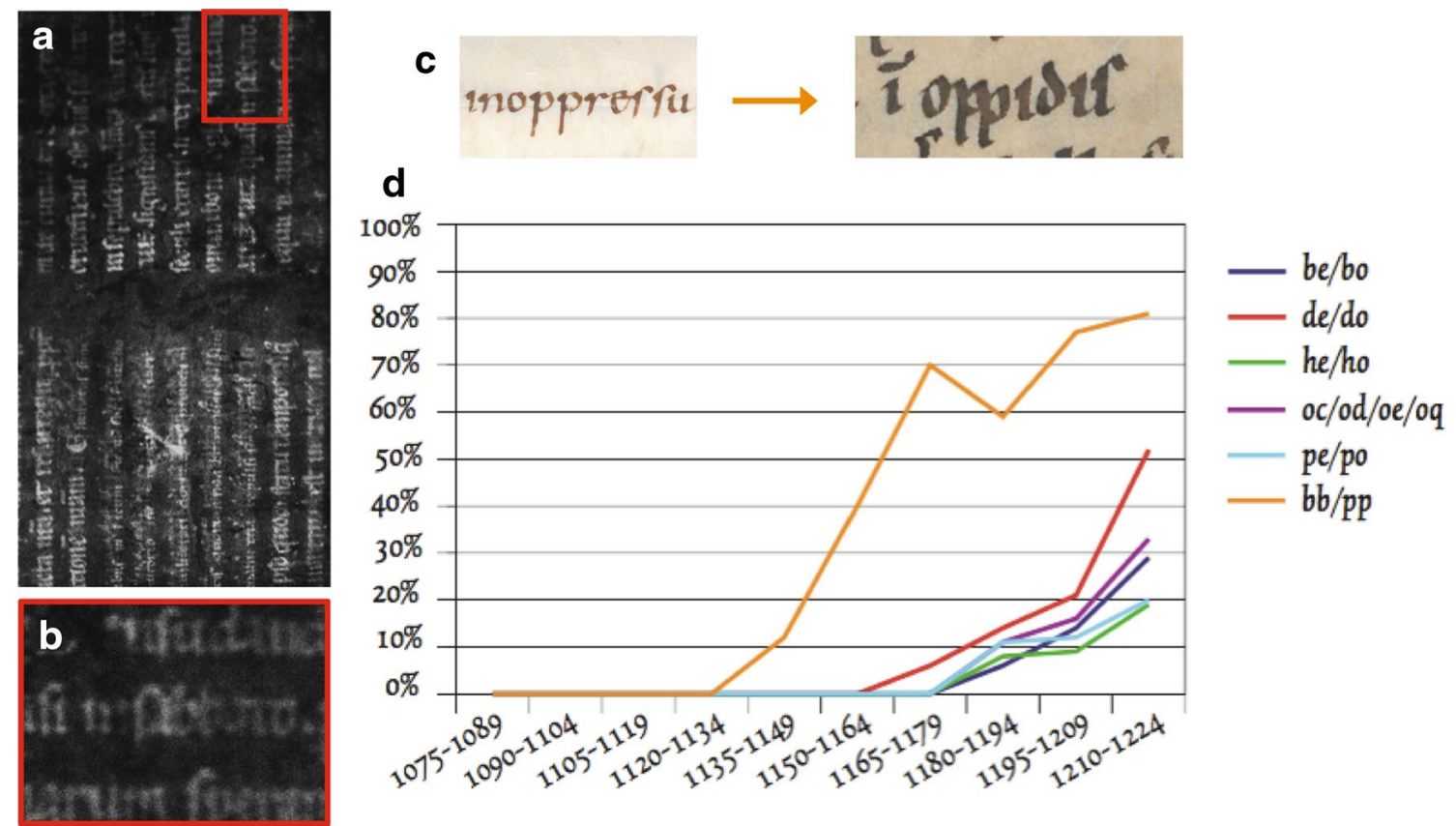

Fig. 4 Biting or fusion process. Calcium distribution map of $635 \mathrm{G} 5$ (a) with the letter pair bb in the word "sabbato" in the red box (b). The graph by Erik Kwakkel (d) shows the process of fusion or biting of the letter pairs bb/pp in yellow. [13] The two examples (c) show the biting process of the letter pair pp, written separately on the left (Lucretius, De rerum natura, ninth century) and written as one entity on the right (Eusebius-Sigebert, Chronicon, second half of the twelfth century)
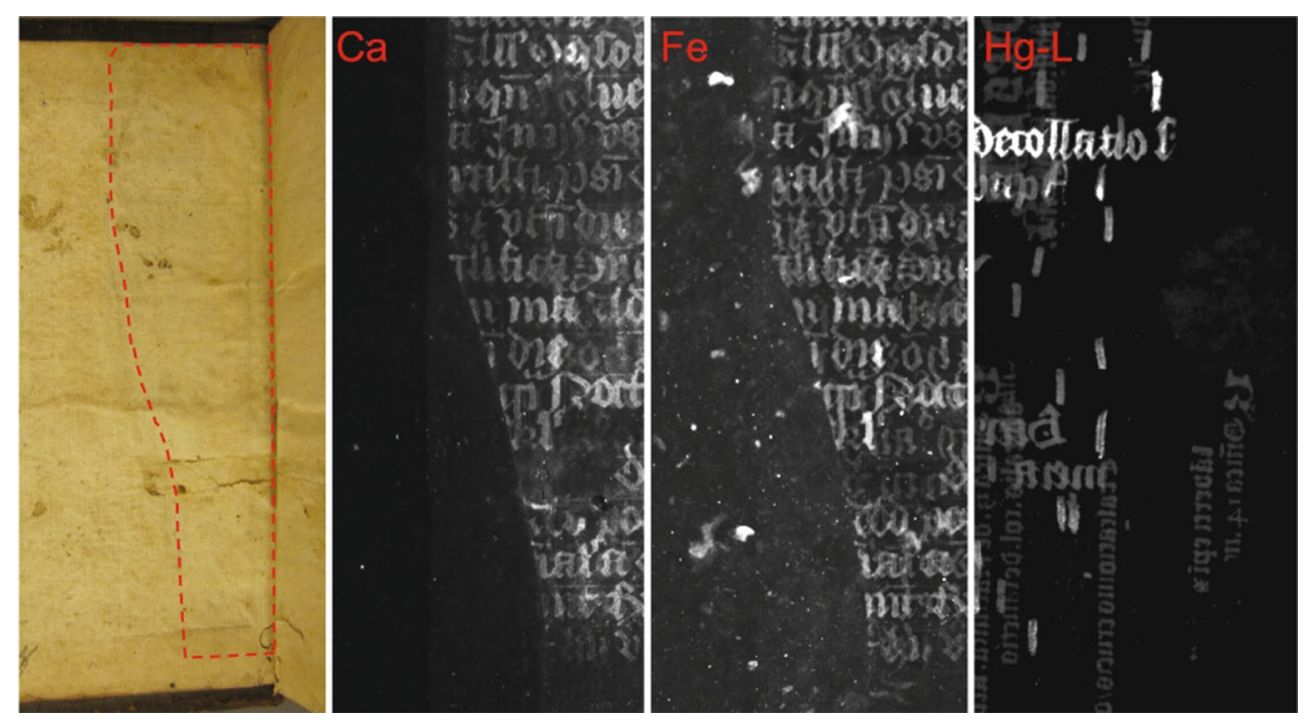

Fig. 5 Corrected calcium, iron and mercury L-lines distribution maps of case study 2,603 G 11

\section{Case study 3-617 F 19}

In this case study a thin strip of manuscript is used as a reinforcement in the parchment bookbinding of an earlymodern printed book. From the inside of the book the far edge of the fragment is visible and two colors are distinguishable: red and green, as seen in Fig. 1.
The iron distribution map in Fig. 6 clearly shows the handwritten text and even though the text overlaps slightly with text from the backside of the fragment it can still be easily read: "Mijn mond sal voertkundigen dijn lof. [G]od wilt dencke[n]", which translates into: "My mouth shall proclaim your praise. God may you think 


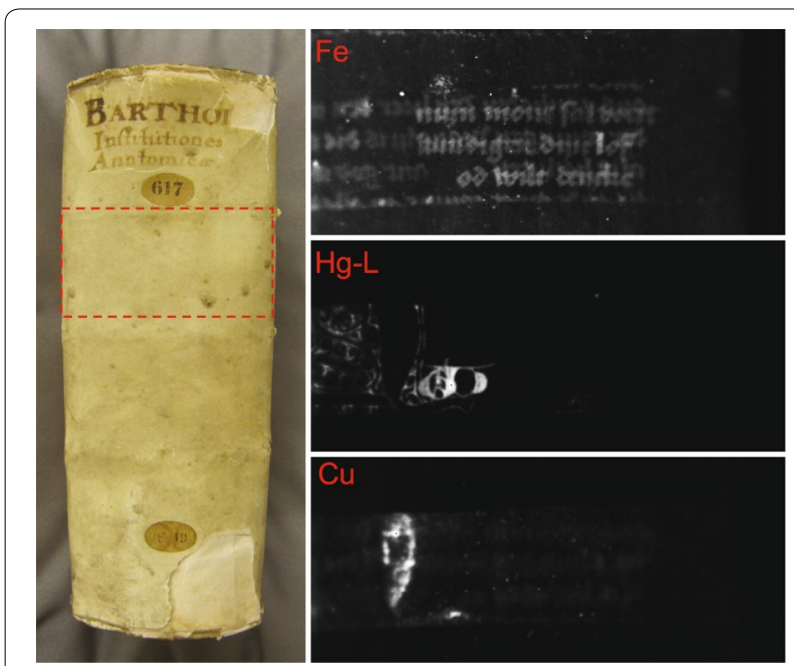

Fig. 6 Corrected iron, mercury L-lines and copper distribution maps of case study 3, 617 F 19 of me." The text is a Book of Hours translated by Geert Grote (died in 1384) to Middle Dutch in the third quarter of the fourteenth century [16]. This fragment is from $c$. 1400 and therefore a remainder of a relatively early manuscript. This date is indicated for example by the shape of the letter a, g and w. Geert Grote is well known as the founder of the Devotio Moderna, a religious movement [17]. The letter $G$ of the word "God" is not visible in the iron map, but it appears in the mercury distribution map as a decorated initial. The copper distribution map shows that the ink contains some traces of copper and some sort of decoration is visible, comparable to the mercury map. Copper corresponds most probably with the green ink seen on the fragment, since green pigments are often copper-based [18]. Based on these observations, we have made a tentative color reconstruction, combining the signals of mercury (red), iron (brown) and copper (greenish blue) on a whitish background. Color values and ratios were attributed manually with image processing software. The reconstruction visualizes both the handwriting along with the decorative initial to the left of the text. The color reconstruction is placed next to the far edge of the fragment that is visible when the book is opened (Fig. 7).

\section{Case study 4-BPG $60 \mathrm{~A}$}

Figure 8 shows the thirteenth-century upper text and the Sophoclean lower text from the tenth century separately visualized based on their chemical composition. In the iron distribution map only the upper text is visible, again difficult to decipher because of the overlap of the recto and verso of the manuscript. The calcium distribution map shows only the Sophoclean text clearly and without overlap. It is possible to recognize the end of Oedipus Tyrannus v. 462

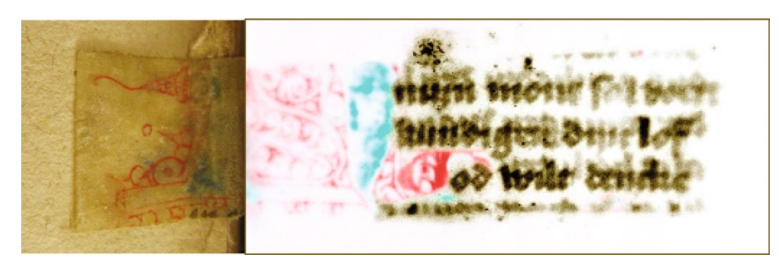

Fig. 7 Tentative color reconstruction of case study 3 (617 F 19). Signals of $\mathrm{Hg}$ (red), Fe (brown) and $\mathrm{Cu}$ (blue) are combined on a white background. Color values and ratios were attributed manually with image processing software. On the left is the far edge of the corresponding fragment

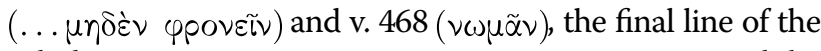
scholium on v. 463 ( scholium on v. 472 ( $x \tilde{n} \rho \varepsilon s \dot{\alpha} \nu \alpha \pi \lambda \dot{\alpha} x \eta \tau$ tol ... ). The potassium distribution map is shown as a comparison, because both the upper and lower text are visible.

\section{Discussion}

The four case studies have successfully demonstrated the potential of the MA-XRF technique to visualize hidden fragments. We have been able to produce elemental maps with sufficient resolution to read the texts. The paint in the first case study, paper in the second case study and parchment bookbinding in the third case study did not interfere significantly with the X-rays and we can see clearly through these materials. We have tried to scan a book with a leather binding, but we could not get a legible picture, because the X-rays were blocked completely by the leather. MA-XRF scanning of the palimpsest provides a very clear picture of the lower text and it enables scholars to read the text better than with the use of a UV lamp, the traditional technique in these cases. The digitization of the manuscript with the use of XRF would be the best solution in order to preserve the codex and allow for more accurate collations of the Sophoclean text.

We have encountered two main problems in the current set-up. First of all, as mentioned in the methods, the focus of the X-ray beam varies with the distance between the X-ray source and the object. Even though we have experience with scanning paintings, the focus of the beam turned out to be more problematic than expected. Neither the book spine, nor the hidden fragment has a straight surface and since we are dealing with small letters and a desire for high resolution images, the focus of the beam becomes an issue (Fig. 9). The X-ray source and detector are mounted on the scanning head that moves in the XY plane. In the current set-up the movement in the $\mathrm{Z}$ direction is not accurate enough to adjust the distance during the scanning. Even if this was the case, the fragment is hidden, so we do not know in what way to 

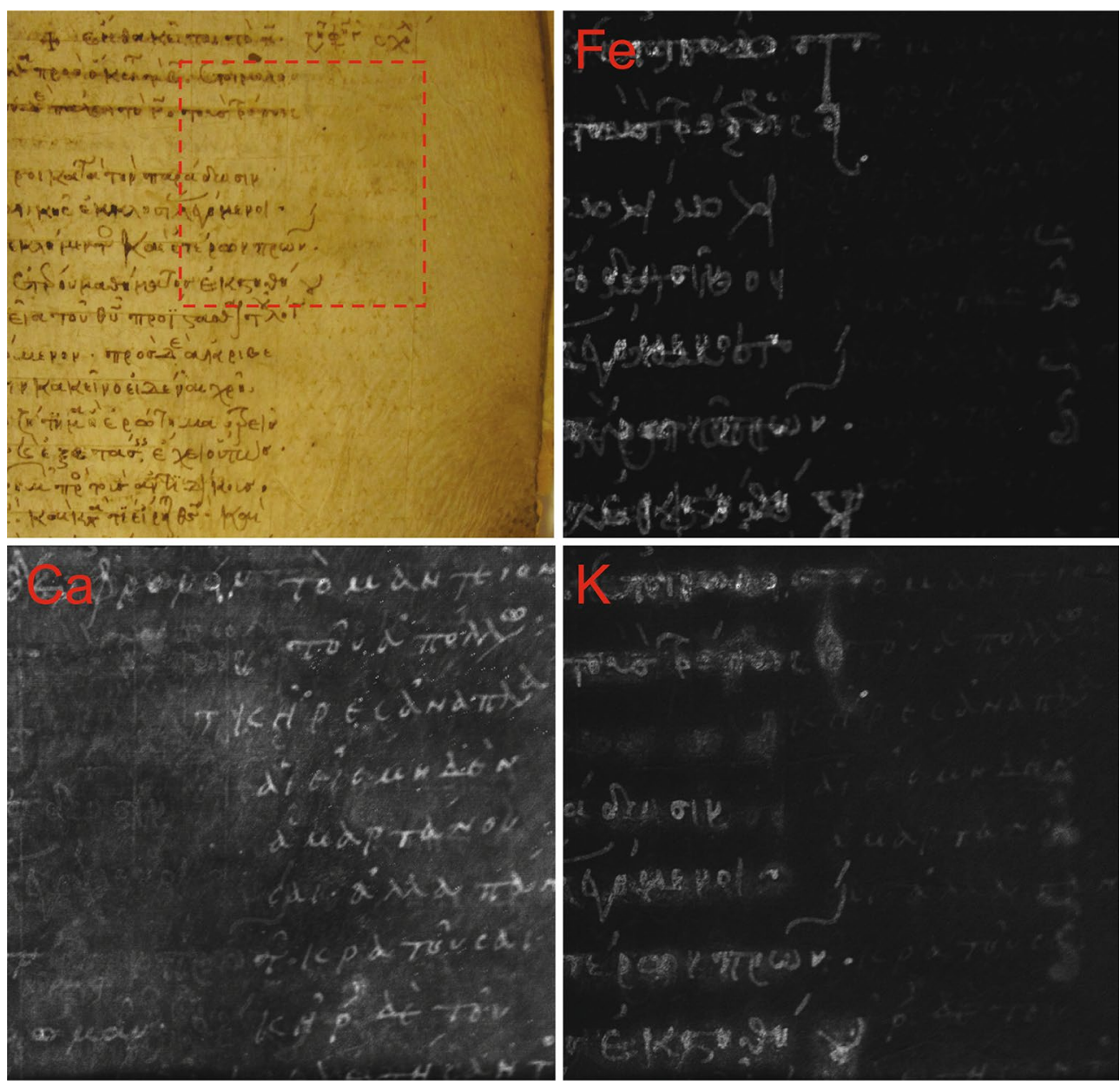

Fig. 8 Corrected iron, calcium and potassium distribution maps of case study 4, BPG 60 A

adjust the distance in the $\mathrm{Z}$ direction. For all the scanned books it took a few tries to find the optimal distance at which most of the fragment was in focus.

The other main limitation of the current set-up is the scanning time. To visualize text and at the same time penetrate material like parchment a small step size and a long dwell time is required. These two requirements result in a very long scanning time, anywhere between 6 and $66 \mathrm{~h}$ per bookbinding. In order to use this technique to scan books in a systematic manner, the scanning speed needs to increase drastically. One way to achieve this is by replacing the current Rh-target X-ray source with a more intense source that produces substantially more X-ray photons per second. While modern synchrotron facilities can produce highly intense $\mathrm{X}$-ray beams of any desired energy, access to these facilities is usually subject to a strict refereeing and selection process, and-even when beamtime is allotted-limited to several days only. For systematic scanning of bookbindings, ample availability of synchrotron-order $\mathrm{X}$-ray intensity is required. Several 'table-top' initiatives have been proposed, of which a set-up based on inverse Compton scattering between a relativistic electron and a laser pulse now seems to be technically feasible [19]. Provided sufficient funding will become available, the intensity would approach that of a bending magnet synchrotron beam and surpass it in the high-energy range relevant for elemental analysis. The Dutch initiative Smart"Light could likely produce high-intensity X-rays based on inverse Compton scattering within 5 years from now [20]. Considering that four examples of limited size but substantial historical interest have been reported in this paper, a revolution in manuscript research can be foreseen once intense table-top X-ray sources become available at universities and research labs. It will be essential, however, to study the effect of an intense X-ray beam on materials such as paper and parchment. 


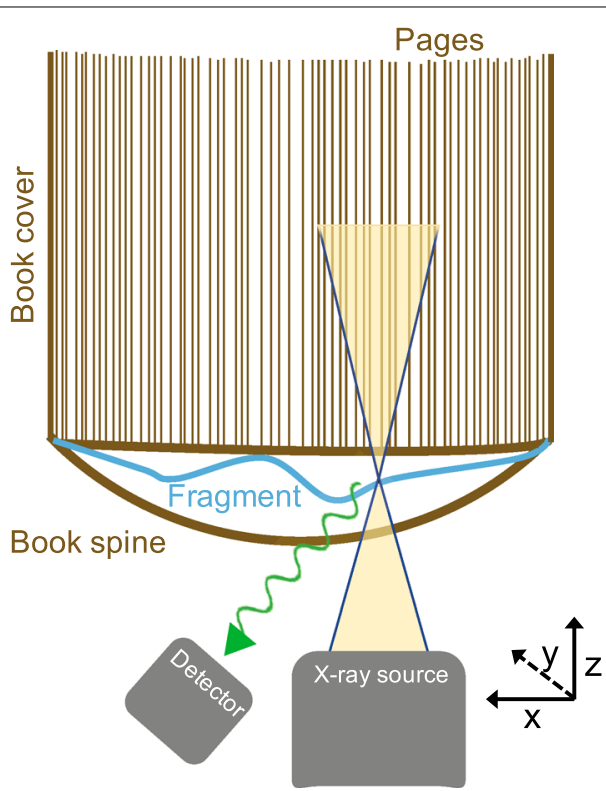

Fig. 9 Schematic representation of the geometry of the scanning head and scanned object. The fragment is hidden underneath the book spine. The $\mathrm{X}$-ray beam is not scaled in this representation: in reality it is smaller. The green waves represent the fluorescence, detected by the detector

\section{Conclusion}

MA-XRF scanning has large potential to visualize hidden fragments of medieval manuscripts in earlymodern books in such a way that we can read, date and localize them. The XRF scanning technique is very suitable for detecting the (trace) metals in medieval inks, while the materials that cover the fragments such as paper and parchment do not block the X-rays. Although we have only shown four case studies in this paper, we already have found texts with substantial historical value such as a 12th-century excerpt of a text by the Venerable Bede and a fragment of a very early Book of Hours from 1400. In addition, we have successfully used the MA-XRF technique to separate the upper and lower text of the famous Leiden palimpsest. Based on this study, we expect that in the near future MA-XRF scanning will enable book historians to systematically investigate fragments and ultimately uncover this hidden library.

\section{Authors' contributions}

JRD wrote the manuscript which was revised by EK, JD and AK. All authors were involved in the execution of the experiment. JRD performed data correcting and analysis. All authors read and approved the final manuscript.

\section{Author details}

${ }^{1}$ Department of Materials Science, Delft University of Technology, Mekelweg 2, 2628 CD Delft, The Netherlands. ${ }^{2}$ Book and Digital Media Studies, Leiden University, P.N. van Eyckhof 4, 2311 BV Leiden, The Netherlands.

\section{Acknowledgements}

We gratefully acknowledge support of the Young Academy of the Royal Netherlands Academy of Arts and Sciences who funded this project. Joris Dik acknowledges the help of the Dutch Organization for Scientific Research (NWO) in the form of a VIDI grant in the Innovational Research Incentive Scheme. Furthermore, we acknowledge the Leiden University Libraries for their cooperation. Particularly, we would like to thank Karin Scheper (conservator Leiden University Libraries), Femke Prinsen (book and paper conservator), Matthijs Holwerda (head Special Collections Services Leiden University Libraries) and André Bouwman (Chief Curator Leiden University Libraries). Lastly, we would like to thank Paolo Scattolin (University of Verona) for sharing his knowledge of the Leiden Palimpsest and Mike Toth (R.B. Toth Associates) and Bill Christens-Barry (Equipoise Imaging LLC) for their help with image processing.

\section{Competing interests}

The authors declare that they have no competing interests.

\section{Funding}

This research project was funded by the Young Academy of the Royal Netherlands Academy of Arts and Sciences. This grant was utilized for the collection and analysis of the data and for writing the manuscript. Furthermore, the development and use of the Bruker M6 XRF scanner was funded by the Dutch Organization for Scientific Research (NWO) in the form of a VIDI grant in the Innovational Research Incentive Scheme granted to Joris Dik.

Received: 28 September 2016 Accepted: 13 January 2017

Published online: 06 February 2017

\section{References}

1. Brownrigg LL, Smith MM. Interpreting and collecting fragments of medieval books. Los Altos Hills: Anderson-Lovelace; 2000.

2. Janssens K, Alfeld M, Van der Snickt G, De NolfW, Vanmeert F, Radepont M, Monico L, Dik J, Cotte M, Falkenberg G, et al. The use of synchrotron radiation for the characterization of artists' pigments and paintings. Annu Rev Anal Chem. 2013;6:399-425.

3. Dik J, Janssens K, Van Der Snickt G, van der Loeff L, Rickers K, Cotte M. Visualization of a lost painting by Vincent van Gogh using synchrotron radiation based X-ray fluorescence elemental mapping. Anal Chem. 2008;80(16):6436-42.

4. Legrand S, Vanmeert F, Van der Snickt G, Alfeld M, De NolfW, Dik J, Janssens K. Examination of historical paintings by state-of-the-art hyperspectral imaging methods: from scanning infra-red spectroscopy to computed X-ray laminography. Herit Sci. 2014;2(1):13.

5. Krug K, Dik J, Den Leeuw M, Whitson Ad, Tortora J, Coan P, Nemoz C, Bravin A. Visualization of pigment distributions in paintings using synchrotron k-edge imaging. Appl Phys A. 2006;83(2):247-51.

6. Hahn O, Kanngießer B, Malzer W. X-ray fluorescence analysis of iron gall inks, pencils and coloured crayons. Stud Conserv. 2005;50(1):23-32.

7. Malzer W, Hahn O, Kanngiesser B. A fingerprint model for inhomogeneous ink-paper layer systems measured with micro-X-ray fluorescence analysis. X-Ray Spectrom. 2004;33(4):229-33.

8. Mitchell CA, Hepworth TC. Inks: their composition and manufacture. London: C. Griffin \& Company; 1904.

9. Kolar J, Štolfa A, Strlič M, Pompe M, Pihlar B, Budnar M, Simčič J, Reissland B. Historical iron gall ink containing documents properties affecting their condition. Analytica chimica acta. 2006;555(1):167-74.

10. Irigoin J. Le palimpseste de sophocle. Revue des Études Grecques. 1951;64(302):443-55.

11. Alfeld M, Pedroso JV, van Eikema Hommes M, Van der Snickt G, Tauber G, Blaas J, Haschke M, Erler K, Dik J, Janssens K. A mobile instrument for in situ scanning macro-xrf investigation of historical paintings. J Anal At Spectrom. 2013;28(5):760-7.

12. Alfeld M, Janssens K. Strategies for processing mega-pixel X-ray fluorescence hyperspectral data: a case study on a version of Caravaggio's painting Supper at Emmaus. J Anal At Spectrom. 2015;30(3):777-89.

13. Kwakkel E, McKitterick R, Thomson R. Turning over a new leaf: change and development in the medieval book. Leiden: Leiden University Press; 2012. 
14. Schuler P-J, Calendarium K. Lexicon des Mittelalters: V Hiera-Mittel Bis Lukanien. Munich: Deutscher Taschenbuch Verlag; 2003.

15. Bergmann U, Knox KT. Pseudo-color enhanced X-ray fluorescence imaging of the Archimedes palimpsest. In: IS\&T/SPIE electronic imaging International Society for Optics and Photonics; 2009.

16. Van Wijk N. Het Getijdenboek van Geert Grote: Naar Het Haagse Handschrift 133 E 21. Leiden: E.J. Brill; 1940.

17. De Bruin CC, Persoons E, Weiler AG. Geert Grote en de Moderne Devotie. Zutphen: De Walburg Pers; 1984
18. Roy A. Artists' pigments. a handbook of their history and characteristics, 2. Washington, DC: National Gallery of Art; 1993.

19. Graves W, Bessuille J, Brown P, Carbajo S, Dolgashev V, Hong K-H, Ihloff E, Khaykovich B, Lin H, Murari K, et al. Compact X-ray source based on burstmode inverse Compton scattering at $100 \mathrm{kHz}$. Phys Rev Spec TopicsAccel Beams. 2014;17(12):120701.

20. KNAW: KNAW-Agenda Grootschalige Onderzoeksfaciliteiten. https:// www.knaw.nl/nl/actueel/publicaties/knaw-agenda-grootschalige-onderzoeksfaciliteiten Accessed 02 Jan 2017.

\section{Submit your manuscript to a SpringerOpen ${ }^{\circ}$ journal and benefit from:}

- Convenient online submission

\section{- Rigorous peer review}

- Immediate publication on acceptance

- Open access: articles freely available online

- High visibility within the field

- Retaining the copyright to your article 